\title{
Back Flashover Analysis of Egyptian 500kV Transmission Lines using Surge Arrestors
}

\author{
Adel Z. EL Dein \\ Electrical Engineering Department \\ Faculty of Energy Engineering, Aswan University \\ Aswan, Egypt \\ azeinm2001@hotmail.com
}

\author{
Noura H. Farah \\ Upper Egypt for Electricity Distribution Co. \\ Aswan, Egypt \\ nora_hft@yahoo.com
}

\begin{abstract}
This paper describes transient performance of the Egyptian $500 \mathrm{kV}$ overhead transmission line (OHTL) during lightning occurrence using ATP-EMTP modeling. Induced voltages across the insulator strings are calculated.

Various parameters that have direct effect on back flashover phenomenon such as the effect of lightning stroke magnitude, the striking distance, front and tail times of lightning stroke impulse, and the tower footing ground system are discussed. Surge arresters were used in this work as a solution for back flashover. The performance of OHTL after connecting surge arrestor has been studied at the instant of the lightning strokes occurrence.
\end{abstract}

Keywords-ATP; back flashover; lightning; induced voltage; tower footing resistance

\section{INTRODUCTION}

The lightning overvoltage is one of important factors causing flashover and damaging the insulators in the transmission line. A lightning flash generally consists of several strokes which are charges, negative or positive from the cloud to the ground. The first stroke is most often more severe than the subsequent stroke [1]. The lightning damages a power apparatus in two ways: the first, it raises the voltage across the apparatus such that the terminals across the struck apparatus spark over causing a short circuit of the system or the voltage punctures through the apparatus electrical insulation, causing permanent damage. The second is the energy of the lightning stroke may exceed the energy handling capability of the apparatus, causing meltdown or fracture [2], [3]. Back flashover is one of the several phenomena which decrease transmission lines reliability. Back flashover occurs when these voltages exceed the line critical flashover [4].

In this paper, the lightning overvoltage in $500 \mathrm{kV}$ single circuit tower is described. The effect of direct lightning on transmission lines have been analyzed with and without the help of surge arrester.

\section{TRANSMISSION SYSTEM MODELING}

The $500 \mathrm{kV}$ transmission line has three sub-conductors per phase and two ground wires. The tower is of flat configuration as shown in Fig. 1. The distance between two adjacent phases is equal to $13.2 \mathrm{~m}$ and the span length is equal to $400 \mathrm{~m}$ [4], [5]. Modeling of transmission line tower is an essential part of the travelling-wave analysis of lightning surges in overhead transmission lines. Tower equivalent circuit of the model consists of main legs and cross-arms as shown in Fig. 2. The transmission line tower model is simulated by ATP-EMTP software.

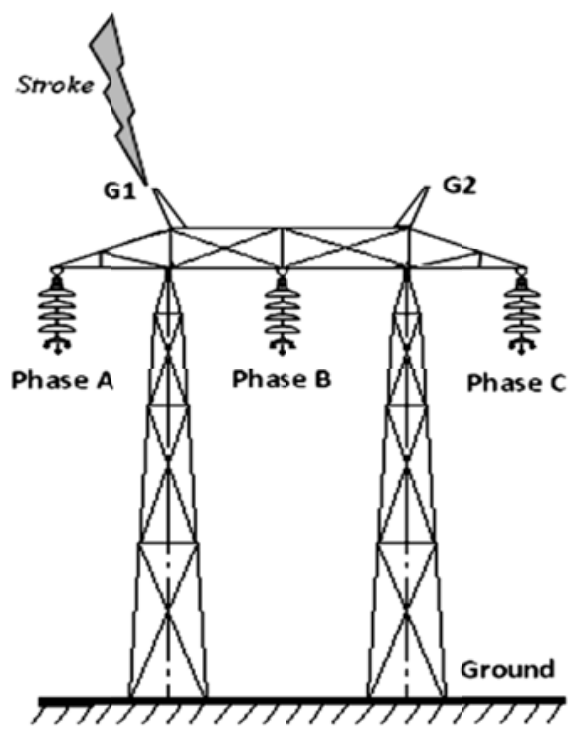

Fig. 1. Egyptian $500 \mathrm{kV}$ transmission tower

\section{A. Surge arrester modeling}

Surge arrester modeling techniques was formed in 1971 by the IEEE Surge Protective Devices Committee's subcommittee on the Application of Surge Protective Devices [6]. IEEE had developed a model in which the non-linear V-I characteristic is represented by two sections of non-linear resistances designated by A0 and A1. These non-linear resistances are separated by an R-L filter [5] as shown in Fig. 3. For fast front surges, the impedance of the R-L filter becomes more significant. For $500 \mathrm{kV}$, the rated voltage of arresters is $(500 \times$ $\sqrt{2}) / \sqrt{ } 3=408.25 \mathrm{kV}$ and the other components values are $\mathrm{L} 1=21.75 \mu \mathrm{H}, \mathrm{L} 0=0.29 \mu \mathrm{H}, \mathrm{R} 1=94.25 \Omega, \mathrm{R} 0=145 \Omega$, and $\mathrm{C}=68.97 \mathrm{pF}[5]$. 


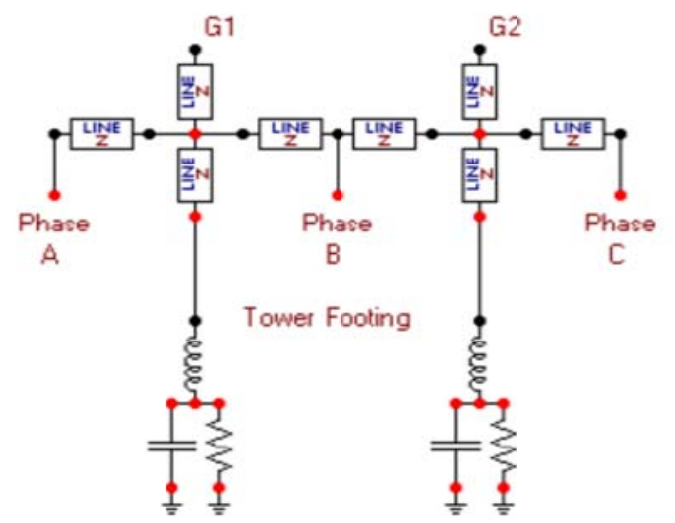

Fig. 2. ATP Model of $500 \mathrm{kV}$ transmission line tower

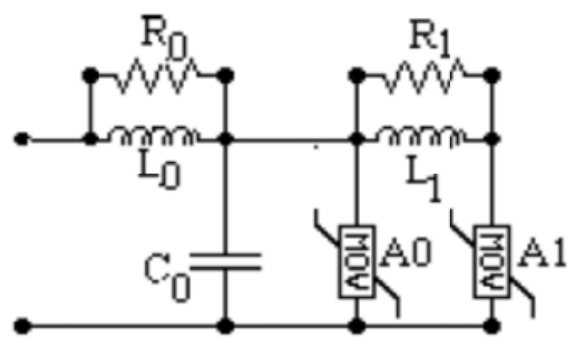

Fig. 3. IEEE surge arrestor model

\section{B. Lightning source modeling}

Lightning-stroke model is represented by a current source with parallel resistance in ATP- EMTP software. The parallel resistance is lightning-path impedance. Lightning-path impedance is selected as $400 \Omega$ [7]. The model used in this study shown in Fig. 4 is the Heidler current model [8], where four characteristics of lightning current quantities at stroking point must be considered: lightning-current peak, maximum of current-steepness, rise time, and decay time.tower footing resistance, and peak of lightning -current The wave shape used in simulation of lightning surge is shown in Fig. 5.

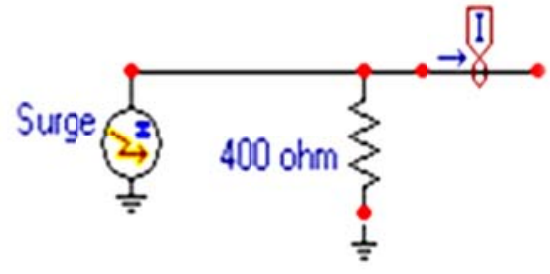

Fig. 4. Lightning stroke Heidler model [10]

\section{Back flashover modeling}

Back flashover pattern is a phenomenon that occurs when lightning stroke terminates at overhead ground wire or tower. A stroke that terminates forces currents to flow down tower and out onto ground wires. Voltages thus build up across line insulation. Back flashover thus occurs across insulator string if the voltages equal or exceed the lines critical flashover voltage (CFO).

The back flashover is represented by parallel switch across the insulator. The parallel switch is modeled and controlled by comparing the volt-time characteristics as in the following equation [9]:

$$
V_{f_{o}}=400 l+\left(710 l / t^{0.75}\right)
$$

where, $l$ is the insulator length in meter and (t) is time in $\mu$ s.

\section{Simulation Results}

The $500 \mathrm{kV}$ single circuit overhead transmission line has been modeled using ATP-EMTP program as shown in Fig. 5. In order to take into account the effect of the AC steady-state voltage of the line on a lightning surge, the transmission line is connected to $\mathrm{AC}$ voltage source via multiphase matching impedance (surge impedance matrix). As the transmission line is terminated with multiphase matching impedance, there is no reflected traveling wave from the far end of the transmission line, and thus, the transmission line is regarded as an infinite line. The parameters of the transmission line used in this study are illustrated in Table I [5].

TABLE I. CARACTERISTICS OF $500 \mathrm{KV}$ LINE CONDUCTORS

\begin{tabular}{|c|c|c|c|c|}
\hline $\begin{array}{c}\text { Conductor } \\
\text { no. }\end{array}$ & $\begin{array}{l}\text { Radius } \\
\text { (mm) }\end{array}$ & $\begin{array}{c}\mathrm{X}- \\
\text { coordinate } \\
(\mathbf{m})\end{array}$ & $\begin{array}{c}\mathrm{Y}- \\
\text { coordinate } \\
(\mathbf{m})\end{array}$ & $\begin{array}{c}R_{\mathrm{dc}} \text { at } \\
20 \mathrm{c}^{0} \\
(\Omega / \mathbf{k m})\end{array}$ \\
\hline A1 & 15.3 & -13.425 & 22.13 & 0.0511 \\
\hline A2 & 15.3 & -12.975 & 22.13 & 0.0511 \\
\hline A3 & 15.3 & -13.2 & 21.74 & 0.0511 \\
\hline B1 & 15.3 & -0.225 & 24.48 & 0.0511 \\
\hline B2 & 15.3 & -0.225 & 24.48 & 0.0511 \\
\hline B3 & 15.3 & 0.0 & 24.09 & 0.0511 \\
\hline $\mathrm{C} 1$ & 15.3 & 12.975 & 22.13 & 0.0511 \\
\hline $\mathrm{C} 2$ & 15.3 & 13.425 & 22.13 & 0.0511 \\
\hline $\mathrm{C} 3$ & 15.3 & 13.2 & 21.74 & 0.0511 \\
\hline G1 & 5.6 & -8.0 & 30 & 0.564 \\
\hline G2 & 5.6 & 8.0 & 30 & 0.564 \\
\hline
\end{tabular}

\section{A. Effect of lightning current magnitude}

It may be observed from Fig. 6 that the magnitude of the induced voltage increases with increasing the peak of the lightning current. An approximately linear relationship between increasing lightning current and induced voltage per phase under various values of lightening current as shown in Fig. 6.

\section{B. Effect of lightning current magnitude}

It may be observed from Fig. 6 that the magnitude of the induced voltage increases with increasing the peak of the lightning current. An approximately linear relationship between increasing lightning current and induced voltage per phase under various values of lightening current as shown in Fig. 6.

When surge arrestor was connected, the over voltages on top of tower 1 , which is caused by various magnitudes of lightening currents, are reduced to lower values reaches approximately $2 \mathrm{MV}$ which is nearby half that in Fig. 7. 


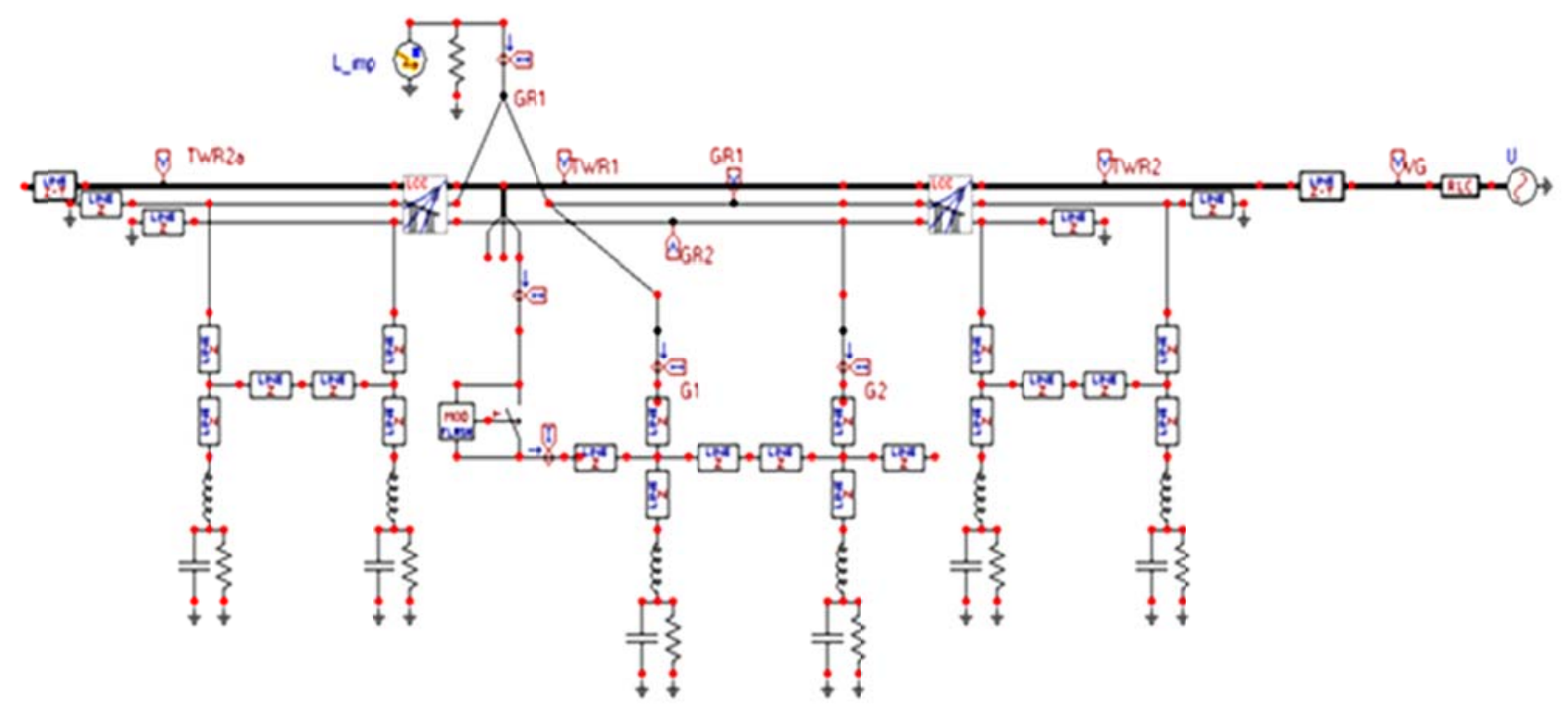

Fig. 5. ATP simulation of $500 \mathrm{kV}$ OHTL system of the case under study

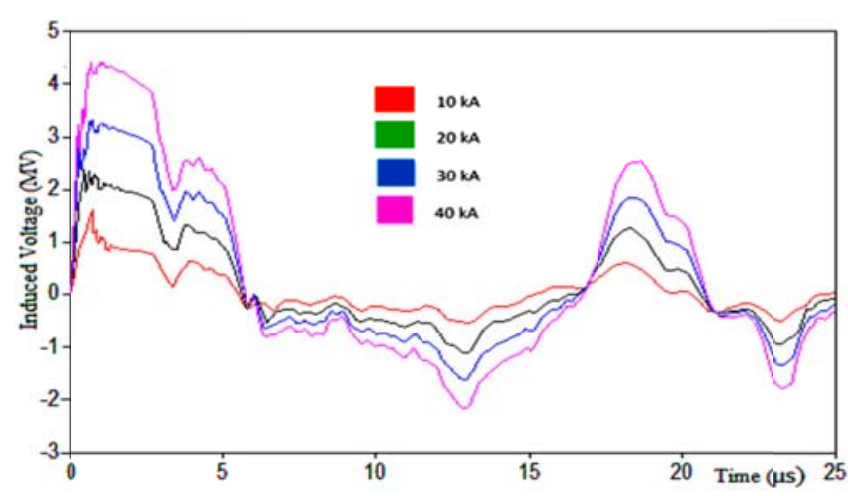

Fig. 6. Variation of induced voltage at top of the tower with various lightning currents at $\mathrm{T}_{\mathrm{f}}=1.2 \mu \mathrm{s}$.

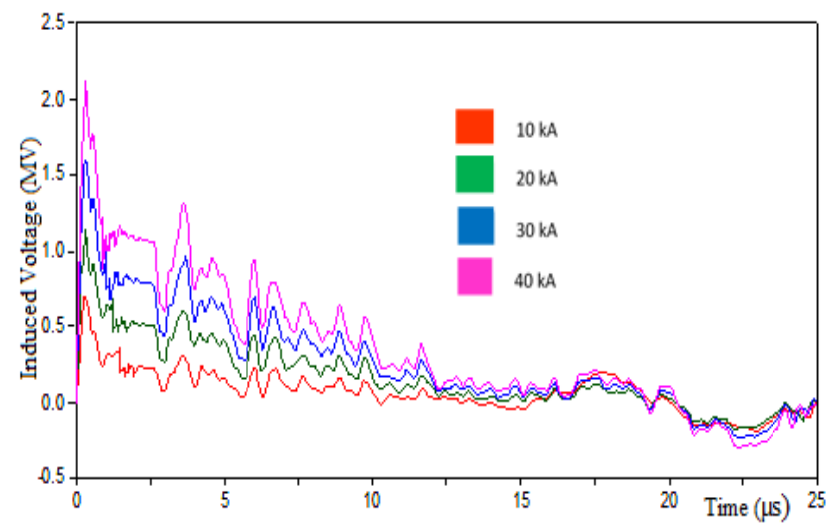

Fig. 7.Variation of induced voltage at top of the tower after using surge arrester with various lightning currents at $\mathrm{T}_{\mathrm{f}}=1.2 \mu \mathrm{s}$
In order to protect the power system apparatus from damage with induced voltage equals about 0.5 to 2 MVA horn gap surge arrester is usually connected across insulators. This protects the power system apparatus from damage. In addition, Fig. 8 compares the induced voltage on line with and without arresters at various magnitudes of lightning current.

It is clear that connecting surge arresters across transmission system have an obvious effect on induced voltages suppression

\section{C. . Effect of front time}

When a lightning stroke hits one of the two ground wires as shown in Fig 9, it is noticed that the shorter front wave time of lightning current $\left(\mathrm{T}_{\mathrm{f}}=1.2 \mu \mathrm{s}\right)$ has the highest induced voltage and that the back flashover voltage across the insulator is approximately 4..5 MV .It may be remarked that the induced voltages decreases with increasing lightning front time.

The Fig. 10 shows when surge arrester is connected, the induced over voltage on top of tower 1 .reaches approximately 2 MV which is nearly half that in Fig. 9.

Fig. 11 illustrates the variation of induced voltage with front time with and without surge arrestors. It may be concluded that the back flashover voltage across the insulator decreases with the increase of front time.

\section{Effect of tail time}

Fig. 12 shows the variation of induced voltage at various tail times of lightning strokes; $20 \mu \mathrm{s}, 40 \mu \mathrm{s}$, and $60 \mu \mathrm{s}$; of same current magnitude of $40 \mathrm{kA}$. It is noticed that the increase of tail time will increase the induced voltage magnitude with neglected percent. Fig. 13 shows the effect of connecting surge arrester to the circuit on the induced over voltages which is caused by impulse lightening with various tail times. 


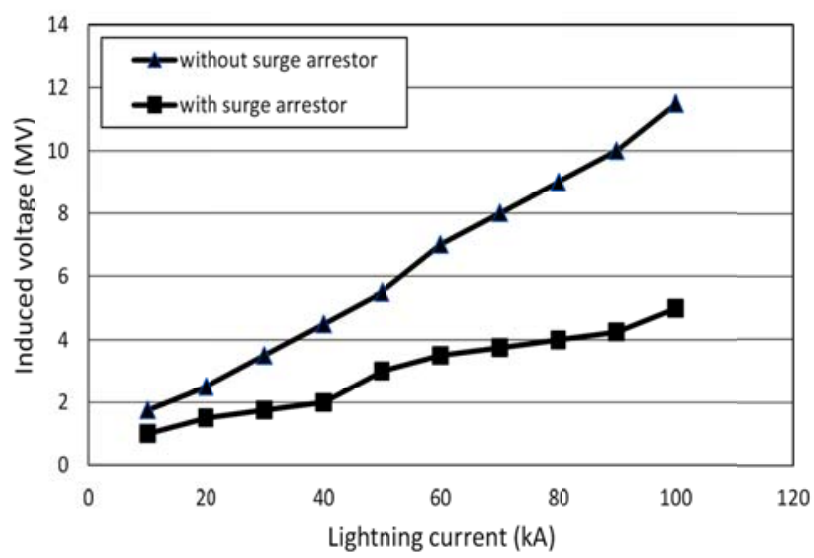

Fig. 8. Peaks of induced voltage at top of the tower versus different lightning currents with and without surge arrestor

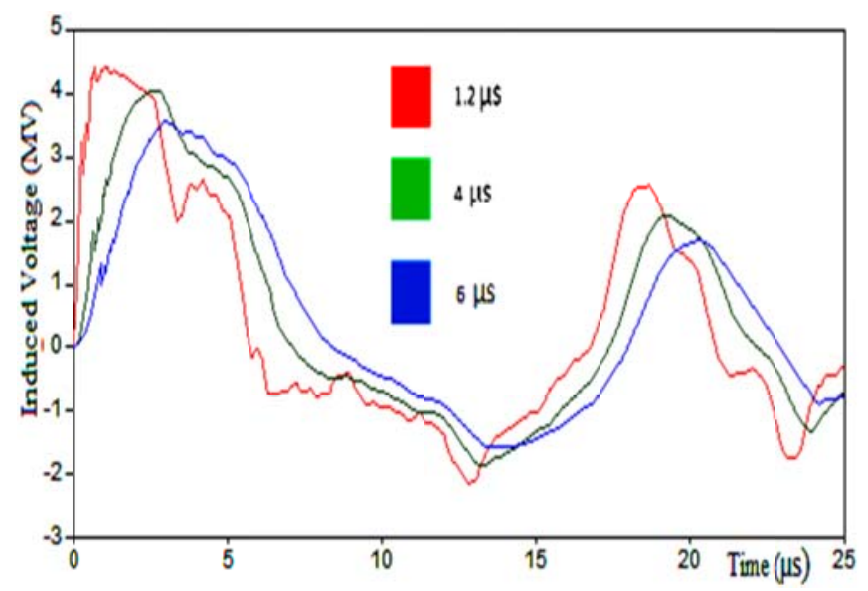

Fig. 9.Variation of induced voltage at top of the tower with various front times at lightning current $20 \mathrm{kA}$

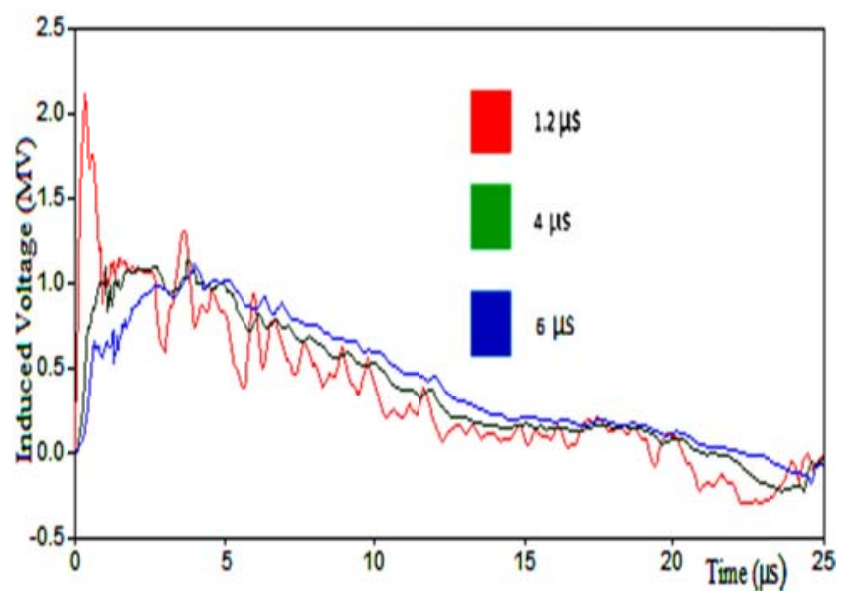

Fig. 10. Induced voltage at top of the tower with various front times after using surge arrestor at lightning current $20 \mathrm{kA}$

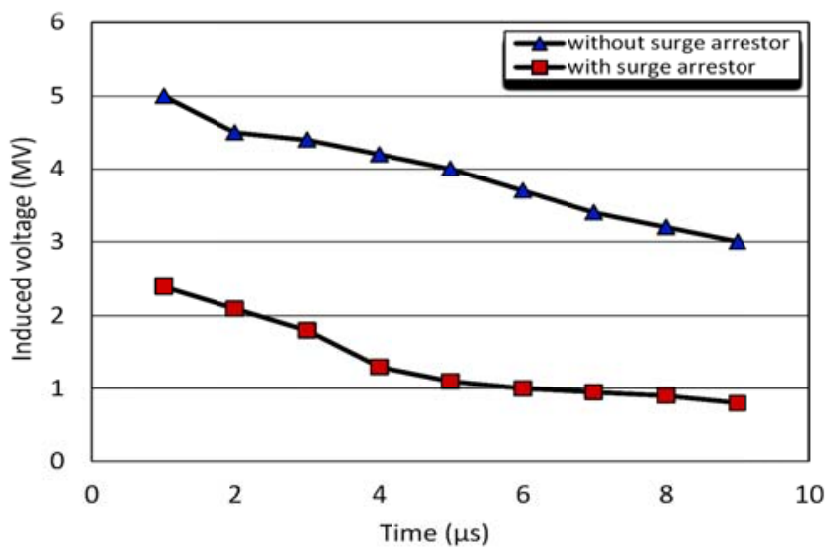

Fig. 11. Peaks of the induced voltage at top of the tower versus front time with and without surge arrestor at lightning current $20 \mathrm{kA}$

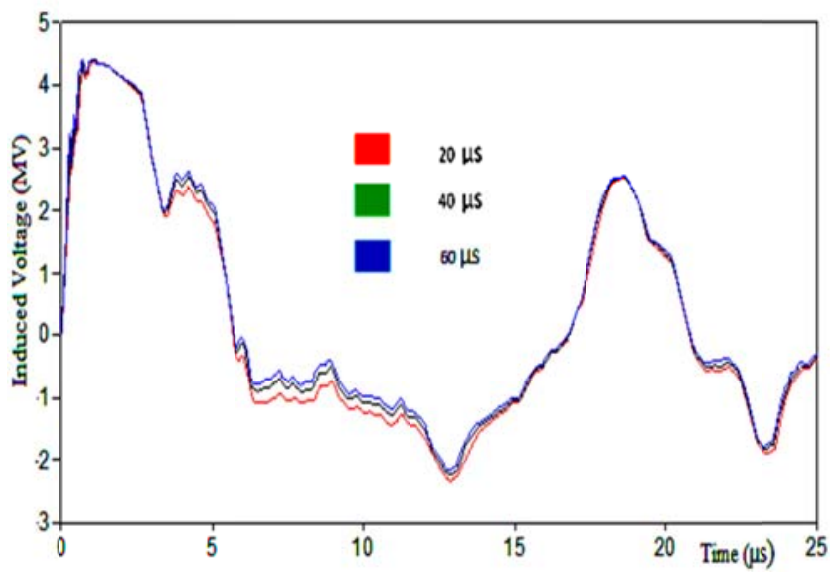

Fig. 12. Variation of induced voltage at top of the tower with various tail times at Lightning current $20 \mathrm{kA}$

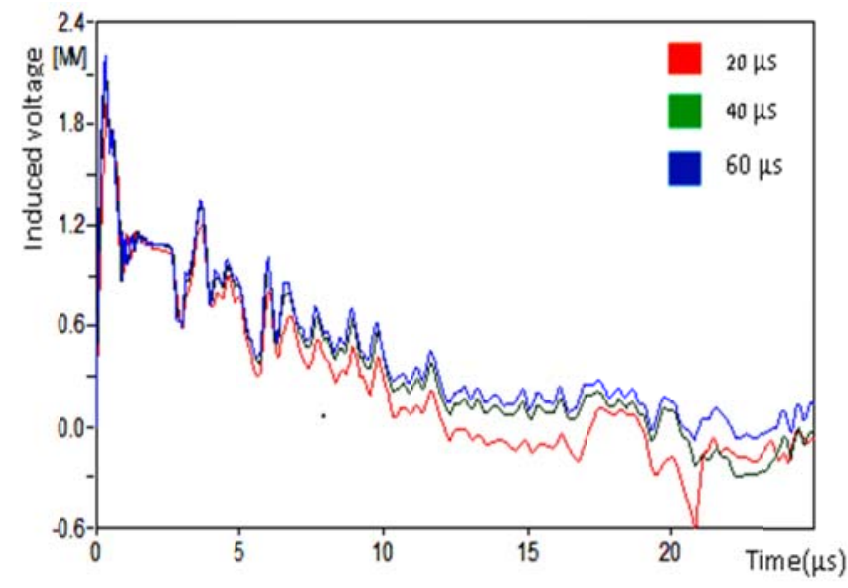

Fig. 13. Variation of induced voltage at top of the tower with various top tail times after using the surge arrestor at lightning current $20 \mathrm{kA}$ 
The induced over voltages reaches approximately $2 \mathrm{MV}$ in shield wire which is lower than that in Fig. 12 before connection surge arresters by $50 \%$.

The use of surge arresters can protect the transmission system and all connected equipment from damaging. The variation of induced voltage with tail times with and without use surge arresters is illustrated in Fig. 14. It may be concluded that the longer the tail time of lightning current has the larger back flashover voltage.

\section{E. Parameters of the ground system}

Vertical and horizontal electrodes which are used at each leg of the transmission line tower as footing grounding system during lightning transient, have many parameters such as: resistivity of the earth in ohm. meter; permittivity of the soil in farad per meter; permeability of the soil in Henneries per meter; electrode length in meter; electrode radius in meter; depth of burial of horizontal electrode in meter [9-10].

Among these parameters, the length of the electrode has the major effect. Fig. 15 shows the induced voltage wave forms on the top of tower 1 for two resistances $4.075 \Omega$ and $1000 \Omega$ and two inductances $0.1 \mathrm{mH}$ and $100 \mathrm{mH}$, respectively.

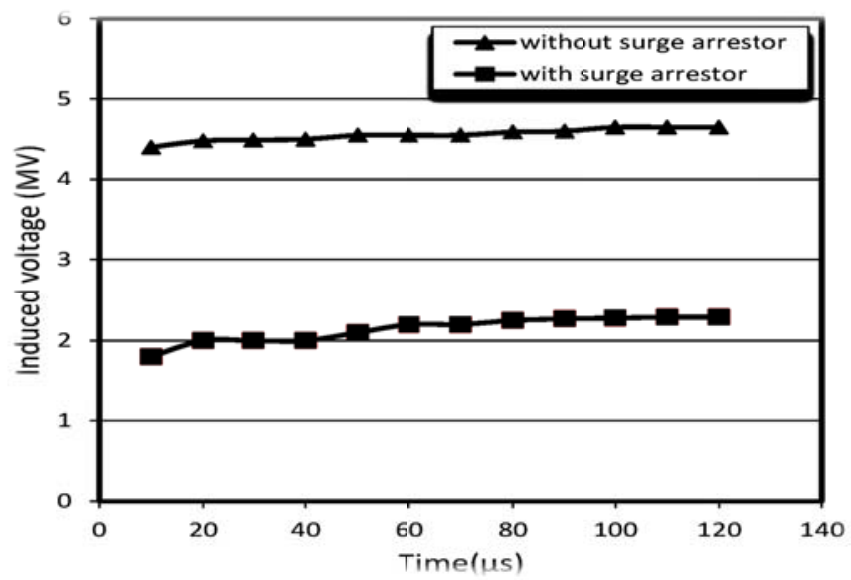

Fig. 14. Peaks of induced voltage versus different tail times with and without surge arresters at lightning current $20 \mathrm{kA}$

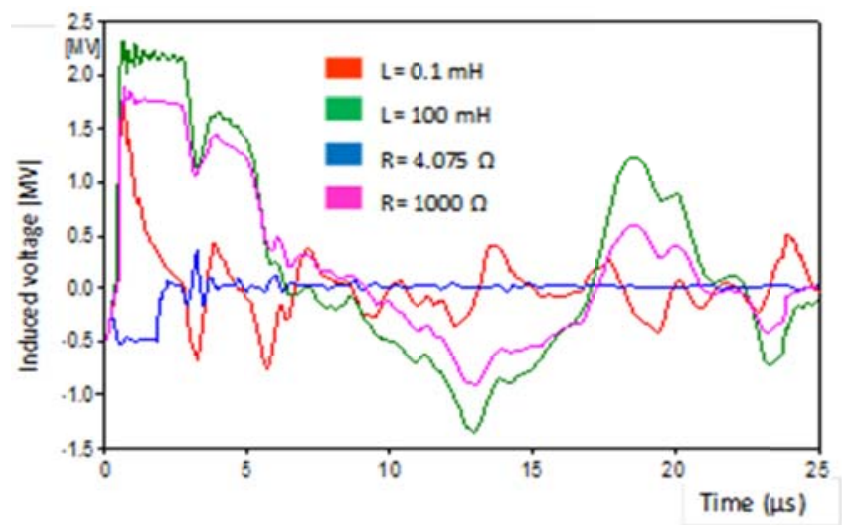

Fig. 15.Variation of induced voltage on phase A at different values of grounding system at lightning current $20 \mathrm{kA}$

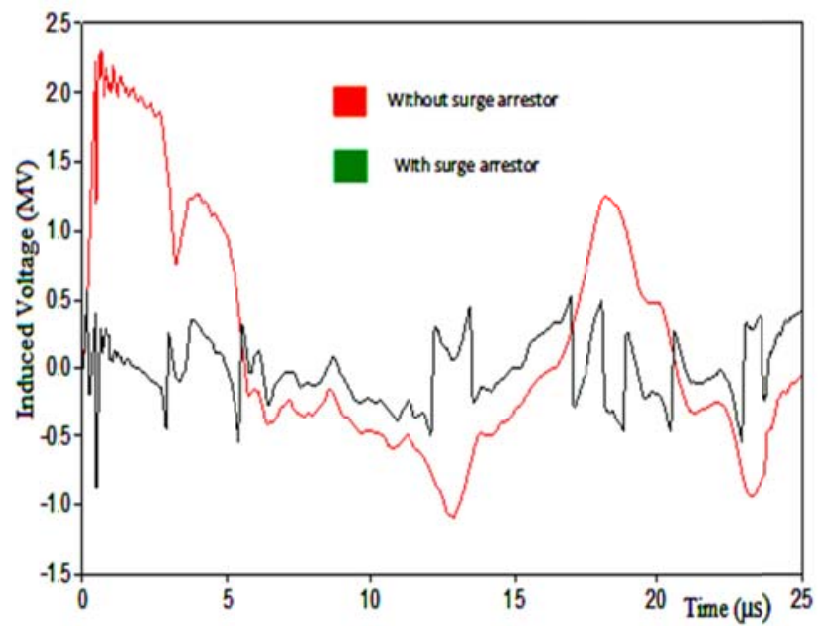

Fig. 16.Variation of induced voltage at insulator of phase A with and without surge arresters at lightning current $20 \mathrm{kA}$

From Fig. 16 ,It is noticed that after connecting surge arresters across the insulator the induced voltage is reduced sharply from maximum voltage of $2 \mathrm{MV}$ to withstand voltage of insulator. The oscillations are corresponding to the capacitance effect during current charging and discharging across the insulator units.

\section{IV.CONCLUSION}

This paper describes affecting of most parameters affected the induced voltage at top of tower of $500 \mathrm{kV}$ transmission system before and after using of surge arresters. The study investigates the effect of lightning current magnitude, front time, and tail time of lightning stroke impulse on back flashover phenomenon. All components of transmission system, under study, are simulated using ATP-EMTP software.

As depicted from simulation results, the induced voltage magnitude is decreases by increasing front time of lightning currents. The effect of tail time is almost neglected on induced voltage magnitude. Connecting surge arresters enhance the performance under lightning condition compared to transmission systems without surge arresters. The induced voltages of $500 \mathrm{kV}$ transmission lines after using surge arresters are reduced approximately by $50 \%$. This protects the high voltage transmission circuits which are subjected to lightning strokes from failure or damaging.

\section{REFERENCES}

[1] Chowdhuri, P., 2001. Parameters of lightning strokes and their effects on power systems. IEEE Trans. Distrib. Conf. Exposition, Atlanta, GA, 1047-1051.

[2] Shwehdi, M., 2008. Computation of lightning flashover \& back flashover voltage levels on $230 \mathrm{kV}$ transmission lines. In: $2^{\text {nd }}$ IEEE International Conference on Power and Energy (PECon 08). Johor Baharu, Malaysia.

[3] Gutierrez, R., Moreno, P., Guardado, L., Naredo, L., 2003. Comparison of transmission line models for evaluating lightning performance. IEEE Bologna Power Tech. Conference, Bologna, Italy. 
[4] Ametani, A., Kawamura, T., 2005. A method of a lightning surge analysis recommended in Japan using EMTP. IEEE Trans. Power Delivery 20 (2), 867-875.

[5] Ossama, G., Adel, Z., Ghada, A., 2010. Parameters affecting the back flashover voltage across the overhead transmission line insulator caused by lightning. In: Proc. of14th International Middle East Power Systems Conference (MEPCON'10), Cairo, Egypt.

[6] Bayadi, A., Zehar, K., Semcheddine, S., Kadri, R., 2006. A parameter identification technique for a metal-oxide surge arrester model based on genetic algorithm. WSEAS Trans. Circuits Syst. 5 (4), 549-554.

[7] Hileman, A., 1999. Insulation coordination for power system. Taylor \& Francies Group 4-5, 373-374
[8] Ametani, A., Kawamura, T., 2005. A method of a lightning surge analysis recommended in Japan using EMTP. IEEE Trans. Power Delivery 20 (2), 867-875.

[9] Dahab, A., Amoura, F., Abu-Elhaija, W., 2005. Comparison of magnetic field distribution of non compact and compact parallel transmission line

configurations. IEEE Trans. Power Delivery 20 (3), 2114-2118.

[10] Abu-Kadir, M., Sardi, J., Wan, W., Hizam, H., Jasni, J., 2009. Evaluation of a $132 \mathrm{kV}$ transmission line performance via transient modelling approach. Eur. J. Sci. Res. 29 (4), 533-539. ISSN 1450-216X. 